\title{
LACTOBACILLUS-FERMENTED PLANT JUICE AS A POTENTIAL INGREDIENT IN COSMETICS: FORMULATION AND ASSESSMENT OF NATURAL MOUTHWASH
}

\section{SASITHORN SIRILUN ${ }^{1}$, BHAGAVATHI SUNDARAM SIVAMARUTHI ${ }^{1}$, NAPHATSORN KUMAR ${ }^{2}$, PERIYANAINA KESIKA ${ }^{1}$, SARTJIN PEERAJAN ${ }^{3}$, CHAIYAVAT CHAIYASUT ${ }^{1 *}$}

${ }^{1}$ Department of Pharmaceutical ScienceS, Faculty of Pharmacy, Chiang Mai University, Thailand. ${ }^{2}$ School of Cosmetic Science, Mae Fah Luang University, Thailand. ${ }^{3}$ Health Innovation Institute, Chiang Mai, Thailand. Email: chaiyavat@gmail.com

Received: 15 August 2016, Revised and Accepted: 29 August 2016

\section{ABSTRACT}

Objective: Oral care cosmetics are essential for all populations and are systematically used to treat oral problems. The chemicals free natural cosmetics are the choice of many people. Thus, this study was aimed to formulate and to assess the natural mouthwash (MW) solution from Lactobacillusfermented Thai medicinal plants juice.

Methods: The selected (betel, green tea, clove, black galingale, mangosteen, and noni) plant juices were subjected to Lactobacillus plantarum mediated fermentation. The fermented plant juices (FPJ) were formulated into MW solution with different concentrations of peppermint oil. MW formulations were assessed for physical appearance, stability, and anti-microbial activities.

Results: About 2\% of peppermint oil in FPJ was found as organoleptically optimum. The pH and refractive indexes of the MWs were not affected during storage and stability assessments. All the FPJ-MWs formulations showed antimicrobial activity against Group A Staphylococcus, and other oral pathogens - Escherichia coli, Streptococcus aureus, and Pseudomonas aeruginosa. Moreover, black galingale, mangosteen, and noni based MW formulas also exhibited anti-candida activity. The MW made from fermented black galingale (Kaempferia parviflora) juice was the most potent antimicrobial formulation with excellent physical stability.

Conclusion: The study concluded that fermented plant-herbal juices can be used as natural MW recipe with $2 \%$ of peppermint oil to improve the flavor and aroma. The formulations were stable, free of microbial contamination, and also exhibited antimicrobial activity. Further extended stability study and clinical trials are necessary to develop a commercial FPJ-based natural MW recipe.

Keywords: Fermentation, Formulation, Lactobacillus, Mouthwash.

(C) 2016 The Authors. Published by Innovare Academic Sciences Pvt Ltd. This is an open access article under the CC BY license (http://creativecommons org/licenses/by/4. 0/) DOI: http://dx.doi.org/10.22159/ajpcr.2016.v9s3.14707

\section{INTRODUCTION}

Oral care cosmetics are essential for all populations and are systematically used to treat oral malodor, prevent tooth decay, and for general sanitation purposes. There are many oral care preparations among that toothpaste and mouthwashes (MWs) are most popular. The healthcare market for health care reaches about $\$ 4.1$ billion and the significant share (73.4\%) from toothpaste and toothbrushes marketing worldwide [1]. Several kinds of natural toothpaste formula and the products are available, whereas very few natural MW formulas are existing.

In general, MW is made out of any active compounds, surfactants, flavor preservatives, and water [2]. The botanical extracts (Camellia spp., Piper betel), essential oils, antibacterials (chlorhexidine, triclosan and cetylpyridinium chloride, fluoride, salts of zinc), and phytochemicals are used as active principles in MW [3]. Some of the MW preparations contain alcohol to its freshness, but many companies claim that their products are alcohol-free and safe for alcohol-sensitive customers. The medicated MW products, which contain chlorhexidine and its salt, are commonly used and prescribed by several dentists. Even though chlorhexidine is considerably safe and efficient, it causes some adverse effects like discoloration of the teeth, desquamation of oral mucosa, taste alteration, burning sensation at oral mucosa and it even affects fibroblast and keratinocyte cell proliferation, which leads to impairment in wound healing [4]. The opposing effects of chemically formulated MW urge the researchers to work on natural products.

In Thailand, several native plants have been traditionally used as mouth sanitizer and oral medicine. Based on the usage and popularity among
Thai people, we have selected six plants for the study such as betel (P. betel L.), green tea (Camellia sinensis [L.] Kuntze), clove (Syzygium aromaticum [L.] Merrill and Perry), black galingale (Kaempferia parviflora Wallich. ex Baker.), mangosteen (Garcinia mangostana L.), and noni (Morinda citrifolia L.).

Betel (P. betel L.) is commonly used as chewing mouth freshener and used in Thai cooking (e.g. Miang-Khum Bai Chaplu). The ethanolic extract of betel leaf has antioxidant, analgesic, antibacterial, and antiinflammatory activity $[5,6]$.

Green tea is obtained from the leaf of $C$. sinensis (L.) Kuntze. It is one of the most popular healthy herbal beverages in the world. Catechins are the most abundant active ingredient present in green tea, possessing many biological activities including antimicrobial activity $[7,8]$.

Clove (S. aromaticum [L.] Merrill and Perry) is one of the traditional herbs used by Thai people for dental pain. Clove oil is also used in dentistry procedures as a disinfectant. It was reported that methanolic extract and flavones of clove are active against periodontal pathogens and also have anti-inflammatory, antioxidant properties [9-11]

Black galingale ( $K$. parviflora Wallich. ex Baker.) is used as a tonic to treat gastrointestinal problems, leucorrhea, and oral diseases in Thai folk medicine. Black galingale extracts exhibit anti-inflammatory effects [12].

Mangosteen (G. mangostana L.) is a famous tropical plant and called "queen of fruit." It is known for antimicrobial, antioxidant, antibacterial, anti-HIV, cytotoxic, anti-inflammatory, and anti-histamine activities [13] 
Noni (M. citrifolia L.) or Yor (in Thai) is another popular health promoting herb in Thailand. Scientific reports suggest that noni can be used in dental care formulations [14,15].

Previous literature suggested that the fermentation increases the bioactivities of medicinal plants and herbs. The bioconversion process will enhance the biological activities of plants. It has been proven that many micro-organisms such as Bacillus subtilis, Lactobacillus spp., and Aspergillus spp. can augment the bioactivity of the medicinal plants [16-18].

Thus, we designed and employed the lactic acid bacteria (LAB) mediated fermentation of selected herbal plants, and formulation of fermented plant juice (FPJ) based on 100\% natural MW. The properties of FPJ formulated MW, and the antimicrobial nature of MW were evaluated.

\section{METHODS}

\section{Plants and microbes}

Betel $(P$. betel L.), green tea $(C$. sinensis [L.] Kuntze), clove (S. aromaticum [L.] Merrill and Perry), black galingale (K. parviflora Wallich. ex Baker.), Mangosteen (G. mangostana L.), and noni (M. citrifolia L.) were freshly purchased from local markets in Chiang Mai, Thailand. The plant materials were referred with herbarium specimens of Faculty of Pharmacy, Chiang Mai University to ensure the species. LAB, Lactobacillus plantarum, was obtained from Health Innovation Institute. Escherichia coli American Type Culture Collection (ATCC) 25922, Staphylococcus aureus ATCC 25923, Pseudomonas aeruginosa ATCC 27853, and Candida albicans ATCC 90028 were acquired from ATCC through a local dealer. Salmonella spp., Clostridium perfringens, and Group A Streptococcus were obtained from Health Product Research and Development Unit, Faculty of Pharmacy, Chiang Mai University.

\section{Fermentation process}

The plant materials were separately cleaned, chopped and decontaminated by soaking in potassium permanganate solution for 30 minutes, and then thoroughly washed with clean water. This was followed by ozone water treatment for 20 minutes. Then, plant materials were mixed with water and honey at the ratio of 3:10:1 (plants:water:honey). The mixture was inoculated with $10 \%$ of L. plantarum culture and kept for fermentation at room temperature in an anaerobic condition for 3 months. After fermentation, the fermented solution was initially filtered through the cotton sheet, followed by Whatman No.1 filter paper to obtain the fermented plants juice (FPJ). FPJ was evaluated for physical appearance, $\mathrm{pH}$, and refractive indices.

\section{Preparation of MW solution with FPI}

The model MW solutions were prepared using FPJ with different concentrations of peppermint oil ranging from $0.1 \%$ to $3.0 \%$. The favorable concentration of peppermint oil provides the pleasant flavor, taste, and smell to formula. The peppermint oil in water served as control.

\section{Physical properties and stability of MWs}

The physical appearances of MWs were determined by the organoleptic method for color, smell, and taste. The $\mathrm{pH}$ of the formulations was measured by $\mathrm{pH}$ meter (Metrohm, Switzerland). The refractive indices of the formulations were measured by a refractometer (ATAQO, Japan; model: $1 \mathrm{~T}$ ) at $25^{\circ} \mathrm{C}$. Physical stability of the MWs was studied in two phases such as (i) accelerated stability study by heating-cooling cycle (incubated at $4^{\circ} \mathrm{C}$ and $45^{\circ} \mathrm{C}$ for $24 \mathrm{hrs}$ each; 6 cycles) and (ii) short-term stability study by incubating the MW preparations at $4^{\circ} \mathrm{C}, 30^{\circ} \mathrm{C}$ and $45^{\circ} \mathrm{C}$ for 28 days. Then, the samples underwent a physical examination, $\mathrm{pH}$, and refractive index assessments.

\section{Microbiological safe}

The MW preparations were analyzed for microbial contamination. The samples were assessed for the total microbial count, yeast and mold, MPN coliforms, E. coli, Salmonella spp., S. aureus, Clostridium perfringens, and $P$. aeruginosa by a standard plating method. Tryptic Soy Agar and Sabouraud Dextrose Agar media (HiMedia) were used for bacterial and yeast and mold culturing, respectively [19].

\section{Antimicrobial activity of MW}

The MWs were screened for antimicrobial activity against E. coli, S. aureus, P. aeruginosa, Group A Streptococcus, and C. albicans by minimum inhibitory concentration (MIC) method (EUCAST) $[20,21]$. Briefly, MW samples were diluted with phosphate buffer saline and treated against test organisms, and incubated at $37^{\circ} \mathrm{C}$ for $24 \mathrm{hr}$. After incubation, the MIC (in terms of dilution) of MW samples against test organisms was recorded.

\section{Statistical analysis}

All the values were denoted as mean \pm standard deviation. Data were analyzed using SPSS 17.0 for windows ${ }^{\circledR}$ (2009 SPSS Inc., Chicago, IL, USA) by analysis of one-way analysis of variance. Differences were considered as significant at $\mathrm{p}<0.05$.

\section{RESULTS}

After the fermentation of the six plants by L. plantarum, the FPJ were filtered and a free-flow liquid with characteristics smell was obtained. The physical appearance, $\mathrm{pH}$ and refractive indices of FPJs are shown in Table 1. The $\mathrm{pH}$ of FPJs was in the range of 2.97-3.97, and the refractive index was in the range of 1.33-1.35. The fermented juices of betel, green tea, clove, black galingale, mangosteen, and noni appeared to be clear yellow, clear orange, brown, reddish orange, reddish brown, and bright orange color, respectively. The smell of the FPJs varied depending on the raw material, and the taste of the FPJs was mostly acidic (Table 1).

The FPJ based MWs were formulated with different concentrations of peppermint oil $(0.1-3.0 \% \mathrm{w} / \mathrm{w})$ and the color, aroma, and taste were determined by organoleptic method (data not shown). Based on the evaluation, FPJ-MW formulation with $2 \%$ of peppermint oil was selected for further analysis, and $2 \%$ peppermint oil in water was used as a control. The physical appearance, $\mathrm{pH}$ and refractive indices of selected FPJ-MW were shown in Table 2. The appearances of FPJ-MWs were as same as respective FPJs. The $\mathrm{pH}$ of FPJ-MWs was in the range of 2.814-3.753; there was a slight change in $\mathrm{pH}$ of FPJ-MWs compared to FPJs. The $\mathrm{pH}$ of control formula was 6.98. The refractive indices of FPJ-MWs were in the range of 1.33-1.35, and we noticed a slight change in the refractive indices of FPJ-MWs than their respective FPJs. The refractive index of control formula was 1.40 (Table 2).

The stability of FPJ-MWs has been calculated by accelerated stability study and short-term stability study. The accelerated stability study

Table 1: Physical properties of the Lactobacillus-fermented plant juices

\begin{tabular}{|c|c|c|c|c|c|}
\hline \multirow[t]{2}{*}{ Plant used } & \multicolumn{3}{|c|}{ Physical appearance } & \multirow[t]{2}{*}{ pH } & \multirow[t]{2}{*}{ Refractive index } \\
\hline & Color & Smell & Taste & & \\
\hline Betel & Clear yellow & Characteristic & Acidic & 3.01 & 1.34 \\
\hline Green tea & Clear orange & Tea scent & Acidic & 3.15 & 1.33 \\
\hline Clove & Brown & Clove scent & Hot and acidic & 3.85 & 1.35 \\
\hline Black galingale & Reddish orange & Characteristic & Acidic & 2.97 & 1.34 \\
\hline Mangosteen & Reddish brown & Characteristic & Astringent & 3.97 & 1.33 \\
\hline Noni & Clear orange & Noni scent & Acidic & 3.32 & 1.33 \\
\hline
\end{tabular}


results were revealed in Table 3. There was a minor change in physical appearance, and $\mathrm{pH}$ of some FPJ-MWs was observed, whereas the refractive indices remained unchanged. The $\mathrm{pH}$ of the formula 2 (green tea) was reduced and became more acidic than other preparations.

The MW formulas made with FPJs of betel, green tea, black galingale and noni became more opaque (Table 3 ). The short-term stability evaluation of FPJ-MWs was studied at three different temperatures $\left(4^{\circ} \mathrm{C}, 30^{\circ} \mathrm{C}\right.$ and $\left.45^{\circ} \mathrm{C}\right)$. The results were represented in Fig. 1. No

Table 2: Physical properties of formulated mouthwashes

\begin{tabular}{|c|c|c|c|c|c|}
\hline \multirow[t]{2}{*}{ Formula } & \multirow[t]{2}{*}{ Plant used } & \multicolumn{2}{|c|}{ Physical appearance } & \multirow[t]{2}{*}{ pH } & \multirow{2}{*}{$\begin{array}{l}\text { Refractive } \\
\text { index }\end{array}$} \\
\hline & & Color & Smell & & \\
\hline F0 & - & Opaque white & Mint & 6.98 & 1.40 \\
\hline F1 & Betel & Clear yellow & Mint & 2.91 & 1.34 \\
\hline F2 & Green tea & Clear orange & Mint & 3.03 & 1.33 \\
\hline F3 & Clove & Brownish & Mint & 3.72 & 1.35 \\
\hline F4 & $\begin{array}{l}\text { Black } \\
\text { galingale }\end{array}$ & $\begin{array}{l}\text { Reddish } \\
\text { orange }\end{array}$ & Mint & 2.81 & 1.34 \\
\hline F5 & Mangosteen & Reddish brown & Mint & 3.75 & 1.33 \\
\hline F6 & Noni & Yellow & Mint & 3.18 & 1.33 \\
\hline
\end{tabular}

Table 3: Accelerated physical stability of mouthwash formulations

\begin{tabular}{llll}
\hline Formula & Physical appearance & pH & Refractive index \\
\hline F0 & Phase separation of peppermint oil & 6.99 & 1.40 \\
F1 & Formula became more opaque & 2.92 & 1.34 \\
F2 & Formula became more opaque & 2.67 & 1.33 \\
F3 & Formula remain unchanged & 3.75 & 1.35 \\
F4 & Formula became more opaque & 2.88 & 1.34 \\
F5 & Formula remain unchanged & 3.78 & 1.33 \\
F6 & Formula became more opaque & 3.03 & 1.33 \\
\hline
\end{tabular}

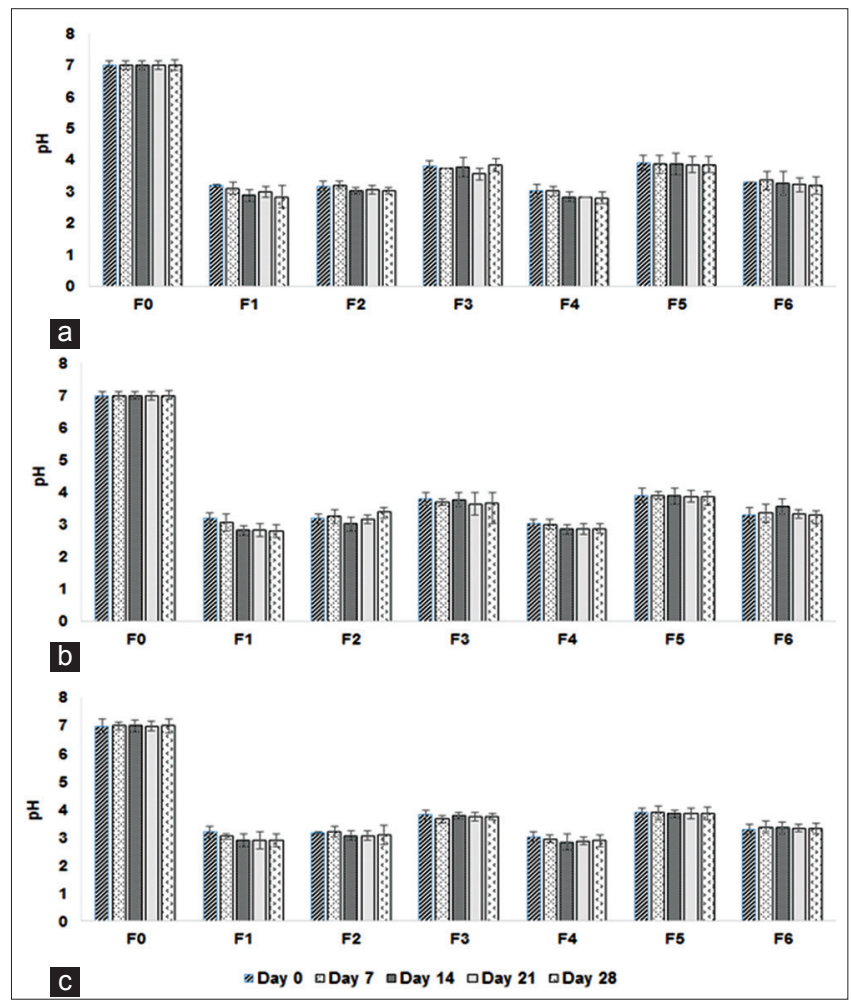

Fig. 1: Alteration in the $\mathrm{pH}$ of mouthwashes containing Lactobacillus-fermented plant juice after stored at $4^{\circ} \mathrm{C}(\mathrm{a}), 30^{\circ} \mathrm{C}$ (b) and $45^{\circ} \mathrm{C}$ (c) for 28 days significant changes were observed among the formulas, except the Formula 1 (betel based FPJ) which became significantly acidic $(\mathrm{p}<0.05)$, whereas Formula 5 (mangosteen-based FPJ) was found to be more stable regarding fluctuation in $\mathrm{pH}$ (Fig. 1)

The microbiological stability of the FPJ-MWs was also tested. None of the formulation was found with analyzed harmful microbes (Salmonella spp., S. aureus, C. perfringens, and P. aeruginosa). In all the formulas, bacterial content was noted especially in F6 $(9.8 \times 103)$. Except F4 $\left(9.1 \times 10^{3}\right)$, all other formulas have not shown any yeast and mold load. The MPN values of the FPJ-MWs were least and are in acceptable range (Table 4).

The antimicrobial activities of FPJ-MWs were analyzed by MIC method. The results indicated that some of the FPJ-MWs exerted the antimicrobial activity against all the test microbes. The MW Formulas 1 and 2 were not active against $C$. albicans. The Formula 4 (black galingale based-FPJ-MW) showed the best antimicrobial activity against tested microorganism except $C$. albicans, while Formula 6 (noni-based-FPJMW), showed potent activity against $E$. coli and $C$. albicans (Table 5).

\section{DISCUSSION}

The selected plants were fermented with L. plantarum and recovered the FPJs. The fermentation process enables the breakdown of complex phytochemicals into a simpler form, which further facilitates the percutaneous absorption. For example, conversion of flavonoid glycoside to flavonoid aglycone forms by $\beta$-glucosidase. In this study, fermentation was mediated by L. plantarum, thus the resultant product with low $\mathrm{pH}$ because of the production of lactic acid (Table 1). The refractive index of liquid products can be used as an indicator of microbiological stability since the microbial growth affect the refractive index by changing the content of sugar as they grow. The refractive index values are constant, for example, the refractive index of water (at $25^{\circ} \mathrm{C}$ ), honey, and peppermint oil is $1.333,1.484-1.504$, and $1.460-1.467$, respectively. Thus, the refractive index of FPJs was recorded (Table 1).

In this study, FPJ-MW formulations were prepared only with FPJs and peppermint oil. Peppermint oil is well known for the phytochemical content and antioxidant, antimicrobial property [22-24]. The anti-oral pathogenic property and application of peppermint oil in dentistry has been reported $[25,26]$. The concentration of peppermint oil is crucial for MW solution preparation. The optimum concentration of peppermint oil was found as $2 \%$. The right level of the peppermint oil provided the pleasant flavor, refreshment, and also blind the sour-acidic smell of the FPJs (Table 2). The formula becomes bitterer when increase the concentration of peppermint oil. The fermentation facilitates the formation of miscible peppermint oil and water (from FPJs) mixture, possibly due to the formation of bioactive surfactants. The $\mathrm{pH}$ and refractive index of the FPJ-MWs were not significantly affected by the addition of $2 \%$ of peppermint oil with raw FPJs (Table 2). The stability study results indicated that all the tested FPJ-MWs were stable regarding $\mathrm{pH}$ and refractive index except Formula 1 (Table 3 and Fig. 1). Some of the FPJ-MWs (F1, 2, 4, and 6) become more opaque, due to the emulsification of peppermint oil (Table 3).

Chavibetol and allylpyrocatechol from betel leaf were exhibiting potent antioxidant activity. Antimicrobial activity of piper betel extract and MW preparation was already reported [27]. Moreover, no physical sign and histological changes were observed after 1 month of allylpyrocatechol supplementation $(25 \mathrm{mg} / \mathrm{kg})$ in mice [28].

Magalhães et al. [7] reported that green tea extract has an ability to reduce dentin erosion and abrasion by inhibiting the matrix metalloproteinase enzyme (MMP; enzymes that degrade collagen, and cause dental erosion) in saliva, and strengthen the dental tissue. A green tea based MW prevents the adherence of microbes in dental suture after extraction of the third molar [8]. The dentifrice (dental preparations for teeth cleaning and polishing) containing green tea catechin reduce the inflammatory markers that are indicators of lipid peroxidation and oxidative protein damage in gingival tissue [29]. 
Table 4: Microbiological assessment of mouthwashes

\begin{tabular}{|c|c|c|c|c|c|c|c|}
\hline Formula & $\begin{array}{l}\text { Total microbial load } \\
(\mathrm{CFU} / \mathrm{ml})\end{array}$ & $\begin{array}{l}\text { Yeast and mold } \\
(\mathrm{CFU} / \mathrm{ml})\end{array}$ & $\begin{array}{l}\text { MPN coliforms } \\
(\mathrm{CFU} / \mathrm{ml})\end{array}$ & Salmonella spp. & S. aureus & C.perfringens & P. aeruginosa \\
\hline F0 & 0 & 0 & 0 & $\mathrm{NF}$ & $\mathrm{NF}$ & $\mathrm{NF}$ & $\mathrm{NF}$ \\
\hline F1 & $<1$ & $<1$ & $<3$ & $\mathrm{NF}$ & $\mathrm{NF}$ & $\mathrm{NF}$ & $\mathrm{NF}$ \\
\hline F2 & $2.2 \times 10^{3}$ & $<1$ & $<3$ & $\mathrm{NF}$ & $\mathrm{NF}$ & $\mathrm{NF}$ & $\mathrm{NF}$ \\
\hline F3 & $<1$ & $<1$ & $<3$ & $\mathrm{NF}$ & $\mathrm{NF}$ & $\mathrm{NF}$ & $\mathrm{NF}$ \\
\hline F4 & $6.2 \times 10^{3}$ & $9.1 \times 10^{3}$ & 0 & $\mathrm{NF}$ & $\mathrm{NF}$ & $\mathrm{NF}$ & $\mathrm{NF}$ \\
\hline F5 & $4.9 \times 10^{2}$ & 0 & 0 & $\mathrm{NF}$ & $\mathrm{NF}$ & $\mathrm{NF}$ & $\mathrm{NF}$ \\
\hline
\end{tabular}

NF: Not found, S. aureus: Staphylococcus aureus, C. perfringens: Clostridium perfringens, P. aeruginosa: Pseudomonas aeruginosa

Table 5: Antimicrobial activity of mouthwashes containing Lactobacillus-fermented plant juice

\begin{tabular}{|c|c|c|c|c|c|}
\hline \multirow[t]{2}{*}{ Formula } & \multicolumn{5}{|c|}{ Minimum inhibitory concentration (MIC) (dilution) } \\
\hline & E. coli & S. aureus & P. aeruginosa & Group A Streptococcus & C. albicans \\
\hline F0 & - & - & - & - & - \\
\hline F1 & $1: 4$ & $1: 4$ & $1: 4$ & $1: 4$ & - \\
\hline $\mathrm{F} 2$ & $1: 2$ & $1: 8$ & $1: 8$ & $1: 4$ & - \\
\hline F3 & $1: 4$ & $1: 8$ & $1: 2$ & $1: 2$ & $1: 1$ \\
\hline F4 & $1: 16$ & $1: 16$ & $1: 32$ & $1: 16$ & $1: 2$ \\
\hline F5 & $1: 8$ & $1: 8$ & $1: 8$ & $1: 4$ & $1: 1$ \\
\hline F6 & $1: 16$ & $1: 8$ & $1: 16$ & $1: 8$ & $1: 4$ \\
\hline
\end{tabular}

E. coli: Escherichia coli, S. aureus: Staphylococcus aureus, P. aeruginosa: Pseudomonas aeruginosa, C. albicans Candida albicans

The methanolic extract of clove demonstrated the antimicrobial activity against periodontal pathogens, Prevotella intermedia and Porphyromonas gingivalis with MIC of 156 and $625 \mathrm{mg} / \mathrm{ml}$, respectively. Whereas, isolated flavones from clove (kaempferol, and myricetin) showed high antimicrobial activity against $P$. intermedia and $P$. gingivalis with MIC of $20 \mathrm{mg} / \mathrm{ml}$. Furthermore, ethanolic extract of clove exerted anti-inflammatory and anti-nociceptive activity [10]. The tannins and flavonoids of clove inhibit phosphodiesterase and prostaglandins activity [30], and eugenol, hydrolysable tannins, and flavonoids are attributed to the antioxidant ability of clove [31]. The extract of black galingale decrease rat paw edema comparable to indomethacin and also strongly inhibits $\mathrm{PGE}_{2}$ release with $\mathrm{IC}_{50}$ of $9.2 \mathrm{mg} / \mathrm{ml} \mathrm{[12].} \mathrm{Murray}$ et al. [13] reported the efficiency of noni juice as an endodontic irrigant. About $6 \%$ of noni juice and EDTA completely removed the smear layer in dentinal tubules, whereas not succeeded with sodium hypochlorite + EDTA solution [14]. The noni juice has significant antimicrobial activity against root canal infecting bacteria Enterococcus faecalis [15].

Due to the antimicrobial property of plant materials, which we used in the fermentation process, and peppermint oil, FPJ-MWs formulas were safe during three months of storage at room temperature (Table 4). The increased load of bacteria in the FPJ-MWs was from starter culture used in the fermentation of plant materials. Since the LAB, L. plantarum is safe and probiotic, LAB cells were not inactivated during MWs preparation. All the FPJ-MWs formulations showed antimicrobial activity against Group A Streptococcus, and other opportunistic oral pathogens E. coli, S. aureus, P. aeruginosa. Moreover, F3-6 also exhibited anti-candida activity (Table 5).

\section{CONCLUSION}

It was concluded that the FPJ, especially herbal juices, can be used as natural MW recipe with $2 \%$ of peppermint oil to improve the flavor and aroma. The formulations were stable, free of microbial contamination and also exhibit antimicrobial activity against oral pathogens. Further extended stability study and clinical trials are necessary to develop a commercial FPJ based natural MW recipe and are in progress.

\section{ACKNOWLEDGMENTS}

We gratefully acknowledged the financial supports and/or inkind assistance from Project Funding of National Research University - Chiang Mai University (NRU - CMU) and National Research
University - Office of Higher Education Commission (NRU - OHEC), Ministry of Education, Thailand, Chiang Mai University (CMU). The authors also wish to acknowledge the Faculty of Pharmacy, Chiang Mai University, Chiang Mai, Thailand.

\section{REFERENCES}

1. Decker C. Bite's back in oral care. GCI 2012;180:34-7.

2. Gaffar A. Oral-care products. In: Barel AO, Paye M, Maibach HI, editors. Handbook of Cosmetic Science and Technology. New York: Marcel Dekker Inc.; 2001. p. 641-2.

3. Lourith N, Kanlayavattanakul M. Oral malodour and active ingredients for treatment. Int J Cosmet Sci 2010;32(5):321-9.

4. Kozlovsky A, Artzi Z, Hirshberg A, Israeli-Tobias C, Reich L. Effect of local antimicrobial agents on excisional palatal wound healing: A clinical and histomorphometric study in rats. J Clin Periodontol 2007;34(2):164-71.

5. Hoque MM, Rattila S, Shishir MA, Bari ML, Inatsu Y, Kawamoto S. Antibacterial Activity of ethanol extract of betel leaf (Piper betle L.) against some food borne pathogens. Bangladesh J Microbiol 2011;28:58-63.

6. Alam B, Akter F, Parvin N, Sharmin Pia R, Akter S, Chowdhury J, et al. Antioxidant, analgesic and anti-inflammatory activities of the methanolic extract of Piper betle leaves. Avicenna J Phytomed 2013;3(2):112-25.

7. Magalhães AC, Wiegand A, Rios D, Hannas A, Attin T, Buzalaf MA. Chlorhexidine and green tea extract reduce dentin erosion and abrasion in situ. J Dent 2009;37(12):994-8.

8. Faria RL, Cardoso LM, Akisue G, Pereira CA, Junqueira JC, Jorge AO, et al. Antimicrobial activity of Calendula officinalis, Camellia sinensis and chlorhexidine against the adherence of microorganisms to sutures after extraction of un-erupted third molars. J Appl Oral Sci 2011;19(5):476-82.

9. Cai L, Wu CD. Compounds from Syzygium aromaticum possessing growth inhibitory activity against oral pathogens. J Nat Prod 1996;59(10):987-90.

10. Tanko Y, Mohammed A, Okasha MA, Umar AH, Magaji RA. Antinociceptive and anti-inflammatory activities of ethanol extract of Syzygium aromaticum flower bud in Wistar rats and mice. Afr J Tradit Complement Altern Med 2008;5(2):209-12.

11. Kale MA, Bindu SM, Khadkikar P. Role of antioxidants and nutrition in oxidative stress: A review. Int J App Pharm 2015;7(1):1-4.

12. Sae-wong C, Tansakul P, Tewtrakul S. Anti-inflammatory mechanism of Kaempferia parviflora in murine macrophage cells (RAW 264.7) and in experimental animals. J Ethnopharmacol 2009;124(3):576-80. 
13. Obolskiy D, Pischel I, Siriwatanametanon N, Heinrich M. Garcinia mangostana L.: A phytochemical and pharmacological review. Phytother Res 2009;23(8):1047-65.

14. Murray PE, Farber RM, Namerow KN, Kuttler S, Garcia-Godoy F. Evaluation of Morinda citrifolia as an endodontic irrigant. J Endod 2008;34(1):66-70.

15. Kandaswamy D, Venkateshbabu N, Gogulnath D, Kindo AJ. Dentinal tubule disinfection with $2 \%$ chlorhexidine gel, propolis, Morinda citrifolia juice, $2 \%$ povidone iodine, and calcium hydroxide. Int Endod J 2010;43(5):419-23

16. $\mathrm{Xu} \mathrm{C}, \mathrm{Ji}$ GE. Bioconversion of flavones during fermentation in milk containing Scutellaria baicalensis extract by Lactobacillus brevis. J Microbiol Biotechnol 2013;23(10):1422-7.

17. Chaiyasut C, Kumar T, Tipduangta P, Rungseevijitprapa W. Isoflavone content and antioxidant activity of Thai fermented soybean and its capsule formulation. Afr J Biotechnol 2010;9:4120-6.

18. Yang EJ, Kim SI, Park SY, Bang HY, Jeong JH, So JH, et al. Fermentation enhances the in vitro antioxidative effect of onion (Allium cepa) via an increase in quercetin content. Food Chem Toxicol 2012;50(6):2042-8.

19. Sirilun S, Chaiyasut C, Kantachote D, Luxananil P. Characterization of non-human origin probiotic Lactobacillus plantarum with cholesterollowering property. Afr J Microbiol Res 2010;4(10):994.

20. European Committee for Antimicrobial Susceptibility Testing (EUCAST) of the European Society of Clinical Microbiology and Infectious Diseases (ESCMID). Determination of minimum inhibitory concentrations (MICs) of antibacterial agents by broth dilution. Clin Microbiol Infect 2003;9:9-15

21. Naragani K, Mangamuri U, Muvva V, Poda S, Munaganti RK Antimicrobial potential of Streptomyces cheonanensis vuk-a from mangrove origin. Int J Pharm Pharm Sci 2016;8(3):53-7.

22. Riachi LG, De Maria CA. Peppermint antioxidants revisited. Food Chem 2015;176:72-81.

23. Tyagi AK, Malik A. Antimicrobial potential and chemical composition of Mentha piperita oil in liquid and vapour phase against food spoiling microorganisms. Food Control 2011;22:1707-14.

24. Rajinder SR, Shushni MA, Belkheir A. Antibacterial and antioxidant activities of Mentha piperita L. Arabian J Chem 2015;8:322-8.

25. Thosar N, Basak S, Bahadure RN, Rajurkar M. Antimicrobial efficacy of five essential oils against oral pathogens: An in vitro study. Eur J Dent 2013;7 Suppl 1:S71-7.

26. Dagli N, Dagli R, Mahmoud RS, Baroudi K. Essential oils, thei therapeutic properties, and implication in dentistry: A review. J Int Soc Prev Community Dent 2015;5(5):335-40.

27. Singgih M, Damayanti S, Pandjaitan N. Antimicrobial activity of standardized piper betel extract and its mouthwash preparation. Int J Pharm Pharm Sci 2014;6(7):243-6.

28. Rathee JS, Patro BS, Mula S, Gamre S, Chattopadhyay S. Antioxidan activity of piper betel leaf extract and its constituents. J Agric Food Chem 2006;54(24):9046-54.

29. Maruyama T, Tomofuji T, Endo Y, Irie K, Azuma T, Ekuni D, et al. Supplementation of green tea catechins in dentifrices suppresses gingival oxidative stress and periodontal inflammation. Arch Oral Biol 2011;56(1):48-53

30. Manthey JA. Biological properties of flavonoids pertaining to inflammation. Microcirculation 2000;7 6 Pt 2:S29-34.

31. Yoshimura M, Amakura Y, Yoshida T. Polyphenolic compounds in clove and pimento and their antioxidative activities. Biosci Biotechnol Biochem 2011;75(11):2207-12 